\title{
Functional Outcomes of Traumatic Complex Acetabulum Fractures with Open Reduction and Internal Fixation: 200 Cases
}

\author{
Keykhosro Mardanpour ${ }^{1}$, Mahtab Rahbar ${ }^{2 *}$, Maryam Rahbar ${ }^{3}$, Nyosha Mardanpour2, \\ Sourena Mardanpour ${ }^{4}$
}

${ }^{1}$ Kermanshah Medical Science University, Kermanshah, Iran

${ }^{2}$ Iran Medical Science University, Tehran, Iran

${ }^{3}$ Tehran Medical Science University, Tehran, Iran

${ }^{4}$ Tehran Azad Medical Science University, Tehran, Iran

Email: kmardanpour@yahoo.com, *rahbarahbar@gmail.com,rahbar_maryam81@yahoo.com,nyoushamardanpour@yahoo.com, sourenamardanpour@gmail.com

How to cite this paper: Mardanpour, K., Rahbar, M., Rahbar, M., Mardanpour, N. and Mardanpour, S. (2016) Functional Outcomes of Traumatic Complex Acetabulum Fractures with Open Reduction and Internal Fixation: 200 Cases. Open Journal of Orthopedics, 6, 363-377.

http://dx.doi.org/10.4236/ojo.2016.612049

Received: October 22, 2016

Accepted: December 27, 2016

Published: December 30, 2016

Copyright $\odot 2016$ by authors and Scientific Research Publishing Inc. This work is licensed under the Creative Commons Attribution International License (CC BY 4.0).

http://creativecommons.org/licenses/by/4.0/ c) (i) Open Access

\section{Abstract}

Objective: Acetabular fractures are common injuries in Iran. We assess the functional outcome of open reduction and internal fixation management of displaced Complex acetabular fractures. Materials and Methods: We analyzed a case series of patients with open reduction and internal fixation (ORIF) for complex acetabular fractures. Two hundred patients (132 men, 68 women) in four age groups including with a mean age of $43.39 \pm 6.18$ years (range 20 - 59 years) and a mean follow-up of $82.34 \pm 12.48$ months (range 18 - 109 months) met the inclusion criteria. Functional outcome at final follow-up was graded assessed according to Harris score. Factors affecting were defined. Results: Anatomic reduction was achieved in 192 hips, imperfect in 8 and poor in none. Radiological outcome revealed excellent results in 128 (64\%) hips, good in eight, fair in five and none in poor. Harris score were excellent in $139(69.5 \%)$ hips, good in $43(21.5 \%)$ and fair in 18 (9\%) and poor in none. The anatomical reduction results had a favorable final functional outcome. (0.003) However, BMI $(\mathrm{P}<0.004)$, fracture pattern $(\mathrm{P}<0.004)$, displaced acetabular fractures $(\mathrm{P}<$ $0.005)$, associated injuries in lower extremity $(\mathrm{P}<0.005)$, finally post-surgery complications $(\mathrm{P}<0.001)$ and adequate physical therapy $(0.004)$ adversely affected the final functional outcome. Deep Vein Thrombosis and Pulmonary Embolism were seen in 6 patients, Avascular Necrosis in 4, local Infection in 6, Heterotopic ossification in 4 and post-traumatic degenerative joint in 5 and sciatic neurapraxia in 2 . Conclusion: Optimal functional and radiological outcomes have been achieved with 
anatomic postoperative reduction. Also experience of specialist, on time surgery and good recovery lead to receiving excellent functional outcome with at least complications.

\section{Keywords}

Complex Acetabular Fracture, Internal Fixation, Open Reduction, Outcome

\section{Introduction}

Major pelvic injuries are predominantly occurred following road traffic collision [1]. Pelvic fractures represent $3 \%$ to $6 \%$ of all fractures in adults and occur in up to $20 \%$ of all polytrauma cases [2] [3] [4] [5]. About 75\% of all pelvic injuries occur in men [6] [7] [8] [9] [10]. The incidence of pelvic fracture resulting from blunt trauma increases with obese patients [11]. A study shows most of the patients with acetabulum fracture were male, in an economically active age group, and were victims of traffic accidents. Edge and/or posterior column fractures were the most frequent types. Associated injuries were common and most of the fractures operated in our service came [12]. These fractures are often associated with other life-threatening injuries [13]. Peltier reported an incidence of $24 \%$ acetabular fractures in his series of adult pelvic fractures. [14] Complex acetabular fracture is not clearly defined in the literature [15]. Some authors restricted its use the term for any fracture that involves both columns of the acetabulum [16]-[24]. However surgical approach is not fixed, the reduction is more difficult and the overall clinical results are known to be worse than simpler fracture patterns [25] [26] [27]. Displacement of the fragmented bones leads to articular incongruity of hip joint, distribution on the articular surface which leads to arthritis of joint [28]. The main goal of treatment of acetabulum fracture is to return the patient to normal functional level and to daily activities. Numerous factors, including fracture type and/or dislocation, femoral-head status, intra-articular osteochondral fragments, injury duration, reduction quality, local complications, associated injuries and surgical approach influence on results [29] [30]. Osteoarthritis of the hip joint, avascular necrosis of the femoral head and heterotopic ossification lead to poor functional outcome despite good fracture reduction and internal fixation [31] [32]. The present study reports results at 10 years follow-up, with an analysis of ORIF management in patients with complex acetabular fractures and determine factors that may contribute adversely to satisfactory functional outcome.

\section{Materials and Methods}

We retrospectively reviewed the cases of all adolescent patients admitted with a diagnosis of complex acetabular fracture in academic institutions in Kermanshah medical University Hospitals from April 2005 to May 2015 undergoing ORIF during about 10 years of follow-up. The approval was not required in accordance with the policy of our 
institution. A total of 200 patients were included and followed prospectively. Data on demographic parameters: age, gender, body mass index (BMI), types of trauma, associated injuries, fracture types, treatment methods, complications and return to normal activities were collected. However, elderly patients with severe osteoporotic bone, undisplaced or minimally displaced fractures $\leq 2 \mathrm{~mm}$, open fracture, pathological fractures, fractures on top of a previous hip disease, other underlining disease and who involved in injuries presenting after 10 days of onset were excluded from the study. Also things that made important limitation in our study leading to incomplete data records were excluded from the study. Trauma etiology was classified as road accident, high fall, and fall from body height or sports-related. The Injury Severity Score (ISS) was determined from emergency medical records [33]. Patient's fracture type was grouped according to Letournel's classification [34]. We included four most common complex acetabular fractures: columns, Posterior Column \& Posterior Wall, Anterior Column \& Posterior Hemi transverse and $\mathrm{T}$ fracture by using conventional radiographs, Computerized Tomography (CT scan) and Magnetic Resonance Imaging (MRI). The minimum follow-up period for every individual case was set to be 18 months. Informed consent was taken from every patient to be involved in the study. Patients included in the study were all those who presented with complex and displaced acetabular fracture of more than $2 \mathrm{~mm}$ which diagnosed radiologically within 10 days of injury.

After admission, initial management was directed to patient's general condition and associated injuries. After making establish the patient's general condition and vital signs of patients, full assessment including clinical and neurological examinations for each patient has been done. Any neurological deficit was recorded. Standard X-ray views and CT cuts were done. The patients who have experience of bleeding are usually not treated for 5 - 10 days following the injury. Because the patient's own clotting mechanisms should have enough time to be effective which is usually within 3 - 5 days. During this period, traction or a system of ropes, pulleys and weights are used to relieve pressure in the joint. All patients with complex fracture associated with unstablehip, loss of congruence articular surface and hip displacement more than $2 \mathrm{~mm}$ should be candidate for surgery with open reduction and internal fixation which is performed to realign the joint with enough stability to allow immediate mobilization and hence preserve the smooth lining of cartilage and avoid subsequent arthritis.

\subsection{Pre-Operative Procedures}

Patients scheduled for surgery undergo a number of tests include: Blood tests for control of stability condition of patient, an electrocardiogram (or EKG) for control of heart activity, a chest $\mathrm{x}$-ray to ensure that the lungs have not been injured and have no fluid in them and that the patient has no infection of the lung, i.e. pneumonia, conventional radiographs, Computerized Tomography (CT scan), or Magnetic Resonance Imaging (MRI). CT scans are particularly useful since they allow the physician to see the fracture in several planes and also see a 3-D model of the fracture. All surgery patients with fractures of the acetabulum are given small preoperative doses of heparin. Patients con- 
tinue to take an anticoagulant (Coumadin) after surgery until the physician has ruled out any further danger of clotting. In addition to these tests, doctors and nurses frequently check the patient's pulses, the feeling in the injured limb, and ask about any strange sensations such as tingling or numbness in the limbs.

\subsection{Operative Procedures}

After general anesthesia all surgeries utilized either ilio-inguinal or extended ilioinguinal or modified stoppa approaches for anterior fracture or both columns fractures, Kocher-Langenbeck or combined approach for posterior and $\mathrm{T}$ fractures. Fixation was done by using plates and screws as the fracture dedicated. (Figures 1-3) Spring plates were applied to reduce and hold a separated medial wall. During this operation, at first bone fragments should be displaced and repositioned (reduced) into their normal alignment. They are then held together with screws or metal plates attached to the outer surface of the bone. For this point, careful detachment of the external rotators and the

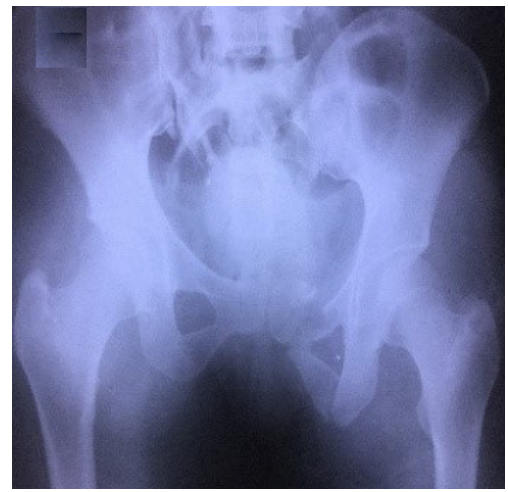

(a)

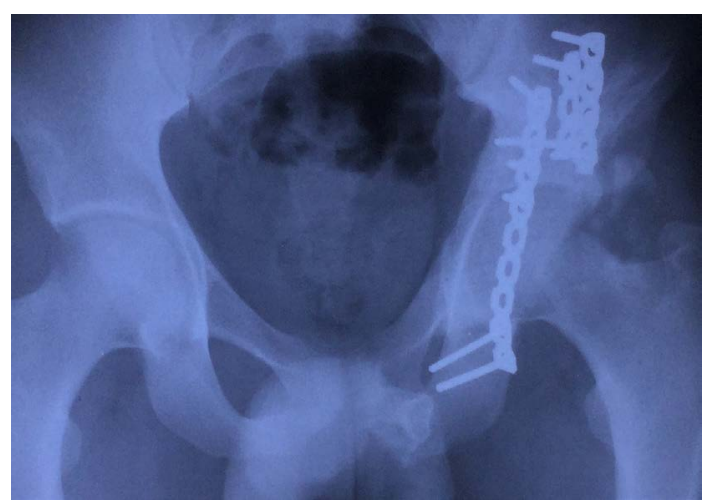

(b)

Figure 1. Male patient, 28 years old, car accident trauma. (a) Pre-operative radiograph of T fracture with high anterior column fracture; (b) immediate post-operative radiograph after surgery (AP).

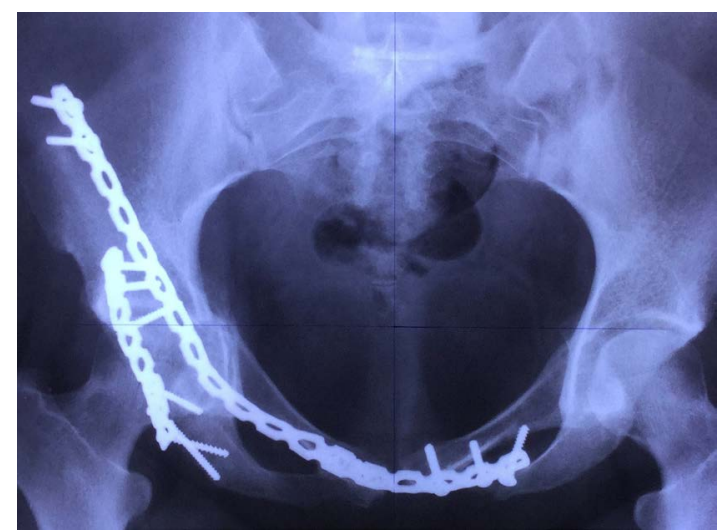

Figure 2. Male Patient, 38 years old, driver, car accident, post-operative radiograph of a Posterior column with transvers fractures (AP). 


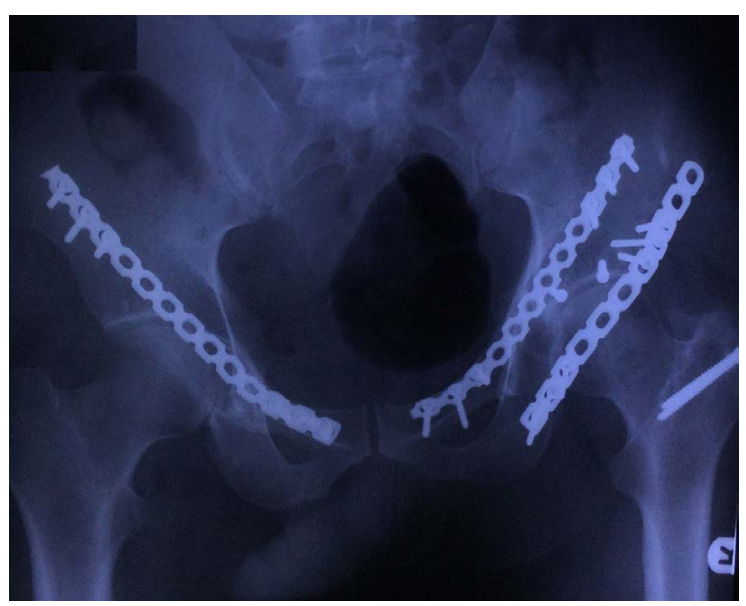

Figure 3. Male patient, 53 years old, car accident, a bilateral posterior columns and unilateral anterior Colum fractures, immediate post-operative radiograph (AP).

piriformis was done while preserving the deep medial femoral circumflex artery. The sciatic nerve was protected by its special retractor. Inspection of the interior of the joint was done through the capsular rent or the posterior wall fracture and was helped by longitudinal traction on the limb combined with trochanteric traction by a T-handled hook. No re-dislocation was attempted. Reduction was done by traction and/or pelvic reduction clamps. Marginal impaction of the articular cartilage was treated by elevation and grafting. Fixation was done by small fragment reconstruction plates and lag screws. Before closure a check by image intensifier was done to assess the reduction and to rule out an intra-articular hardware. Wound closure over suction drains was performed.

\subsection{Post-Operative Care}

Radiographs are usually obtained at the completion of the operation for preliminary confirmation of the reduction. A minimum of an AP pelvis radiograph is obtained in the operating room; the iliac oblique and obturator oblique views can be obtained in the operating room or later. After gait training and before discharge, another AP pelvic radiograph generally is obtained to confirm that loss of reduction has not occurred during ambulation. A single AP pelvis radiograph is obtained at each follow-up examination. The relationship between the femoral head and the roof of the acetabulum was described following Letournel's descriptions as follows: (1) maintained head/roof congruency, (2) loss of parallelism in the upper joint space, (3) loss of parallelism and subluxation of the head and (4) secondary surgical congruence [35]. Postoperative reduction was evaluated by measuring residual displacements on the three postoperative radiographs (anteroposterior and two $45^{\circ}$ oblique Judet views) and graded as anatomical (0 - $1 \mathrm{~mm}$ of displacement), imperfect (2- to 3-mm of displacement) or poor ( $>3-\mathrm{mm}$ displacement) according to Matta [36]. Following surgery, managing the patient's pain and managing any complications that arise due to the injury are primary concerns. Initially, pain medication will be given by injection. Other medications that may be given 
include anticoagulants to thin the blood and avoid the development of blood clots, and Indocin, which prevents bone formation in areas around the muscles. Patients are encouraged to get up and out of bed as soon as possible, since doing so helps to avoid some of the complications associated with these injuries. After about 1 year, if no complications are present, return to sporting activity may be advised. A regimen of physical therapy is followed to maintain muscle strength and range of motion during recovery. Physical therapy is directed toward regaining muscle strength at the hip, especially in the abductors, as this has been shown to correlate well with the final functional outcome. Important branches of the lumbar and sacral nerves may be either stretched or torn, especially in the case of complex acetabulum fractures. Injuries to the nerves result in decreased feeling in a limb and/or difficulty or inability in moving part of the limb. It is difficult to predict whether these nerves will fully recover. However, the majority of patients do regain some sensation and function of the limb within six to eighteen months after their injury.

\section{Complications}

Throughout treatment and recovery, doctors and nurses are watchful for the following potential complications: Deep Vein Thrombosis and Pulmonary Embolism, Pneumonia, Skin Problems resulting from being in one position for a long period of time (bed sore), Muscle Complications due to inactivity, Heterotopic Ossification, Damage to the Head of the Femur and Infection at the site of the surgery. However, Patients who have suffered from a traumatic accident or injury may experience psychological distress over changes in their appearance and physical functioning. The shock of becoming an accident victim may also linger. Difficulty sleeping and coping with the pain associated are more prone to experience psychological difficulty connected with their fracture. We recommend social worker or psychologist for helping to make less patient's stress.

\section{Statistical Analysis}

Statistical analysis was done using SPSS version 16 for Windows (SPSS Inc., Chicago, Illinois). Spearman's correlation was used to detect linear relations between quantitative variables while Mann-Whitney and Kruskal-Wallis tests were used to rank and compare qualitative variables against the median final functional score. A p-value < 0.005 was considered to be statistically significant.

\section{Results}

A total of 200 patients who presented with displaced complex acetabular fractures of more than $2 \mathrm{~mm}$ within 10 days of injury have been included. All patients were operated by open reduction and internal fixation technique. All was available for review and evaluation of results. All cases were managed by a single surgeon experienced in managing pelvic trauma patients. They have been set in four agegroups. Mode of injury inmajority of the cases was road accident 166 (83\%), high fall 23 (11.5\%) and fall from body height or sports-related 11 (5.5\%). Fracture's pattern was in four groups (Figure 4). 


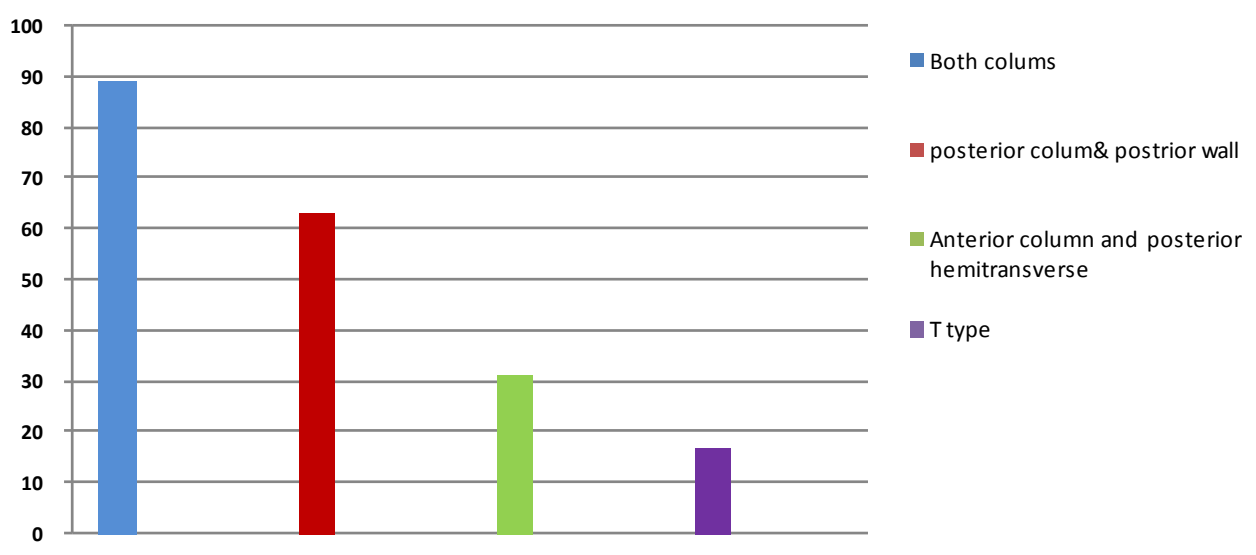

Figure 4. Complex acetabulum fracture types distribution in 200 cases.

115 (67.5\%) patients were operated through Kocher Langenbeck approach, 30 (15\%) through both Kocher Langenbeck and ilio-inguinal approaches, 20 (10\%) through stoppa approach and $55(27.5 \%)$ through the ilio-inguinal and extended ilio-inguinal approaches. The mean duration of surgery was $87 \mathrm{~min}$ (range of $67-139 \mathrm{~min}$ ) with mean blood loss $635(500-1300) \mathrm{mL}$. The mean hospital stay was $6.5(5-10)$ days and mean follow-up was $82.34 \pm 12.48$ months. There was no residual instability or Nonunion at the final follow-up. In 192 (96\%) cases, congruent and anatomical reductions according to Matta were achieved. The remaining 8 patients had incongruent and imperfect reduction. Functional outcomes according to Harris score with a preserved hip was graded as "excellent" in 139 (69.5\%) and "good" in 43 (21.5\%) and fair in18 (9\%) patients and poor in none patients. The final mean Harris hip score was 92.6\% (7198). Radiographically, 128 (64\%) were graded as "excellent", 58 (29\%) as "good" and 14 (7\%) as "fair" and poor in none patients. Correlation between functional outcome and types of complex acetabulum fracture was significant. $(\mathrm{P}<0.003)$ (Figure 5). Also, Correlation between functional outcome with radiological outcome $(\mathrm{P}<0.004)$ and functional outcome with reductional outcome were significant (for both $\mathrm{P}<0.004$ ) (Figure 6, Figure 7).

Excellent prognosis has been achieved the following: BMIless than $25(\mathrm{P}<0.004)$, low degree of initial displacement $(\mathrm{P}<0.005)$, low degree of articular comminution of the acetabulum and damage of thehead of femur $(\mathrm{P}<0.003)$, decrease numbers of associated injuries $(\mathrm{P}<0.005)$, post-surgery complications $(\mathrm{P}<0.001)$ and finally postoperative physical therapy care (0.004) (Figure 8, Figure 9).

Treatment factors affecting the outcome are good quality of the reduction, which ideally restores congruity, and good quality of fixation, which ideally restores stability and adequate postoperative care and rehabilitation programme. Also, in our series, the prognosis has been in risk by presenting complications such as DVT and pulmonary embolism 6 (3\%), infection in in site of surgery was $6(12 \%)$, heterotropic ossification was $4(8 \%)$, sciaticnerve injury in $2(1 \%)$, avascular necrosis of head of femur in $4(8 \%)$ patients and damage of the head of femur was $5(2.5 \%)$. We didn't deal to other complications like chondrolysis, sepsis (Table 1). 


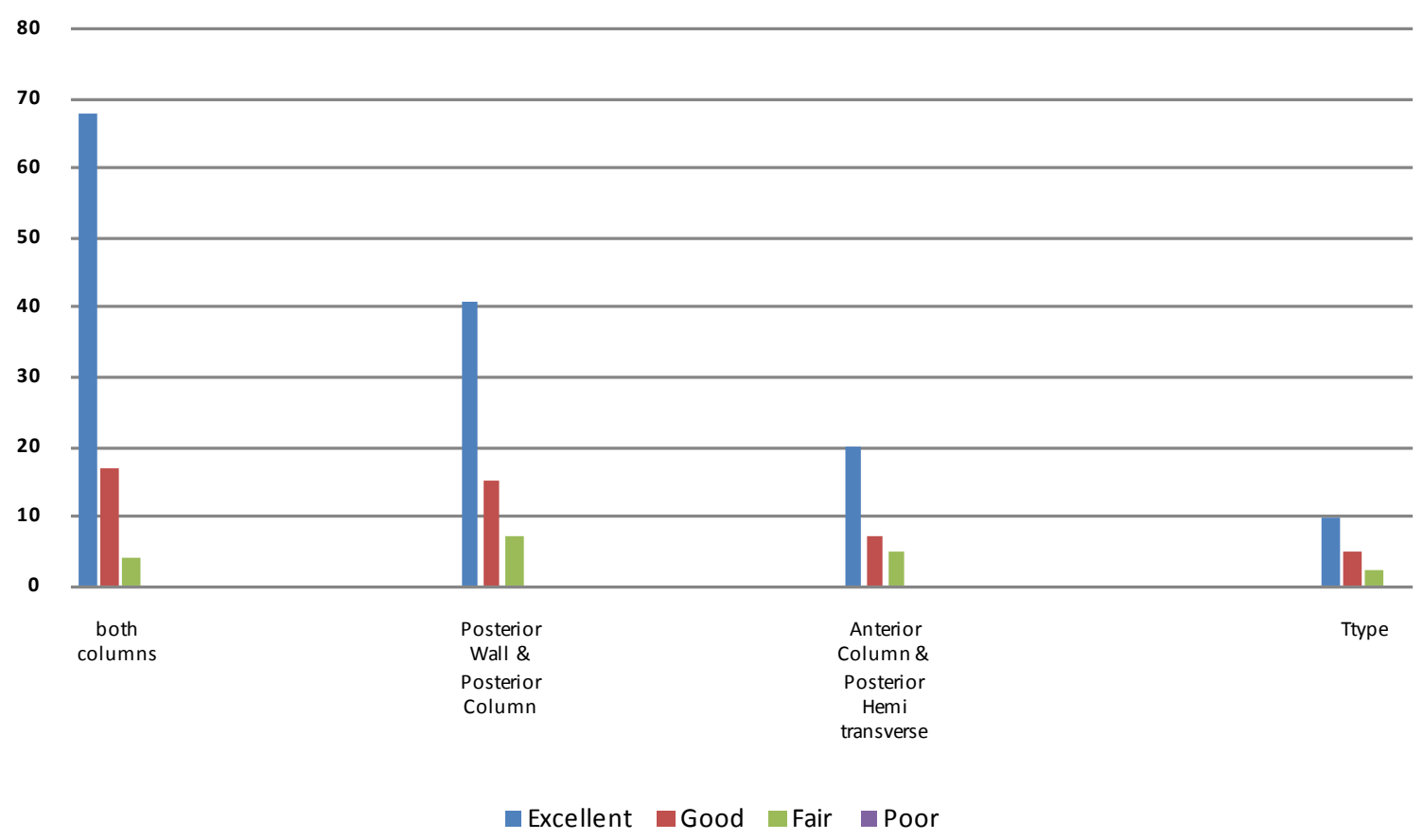

Figure 5. Correlation between functional outcome and types of complex acetabulum fracture in 200 cases $(\mathrm{P}<0.003)$.

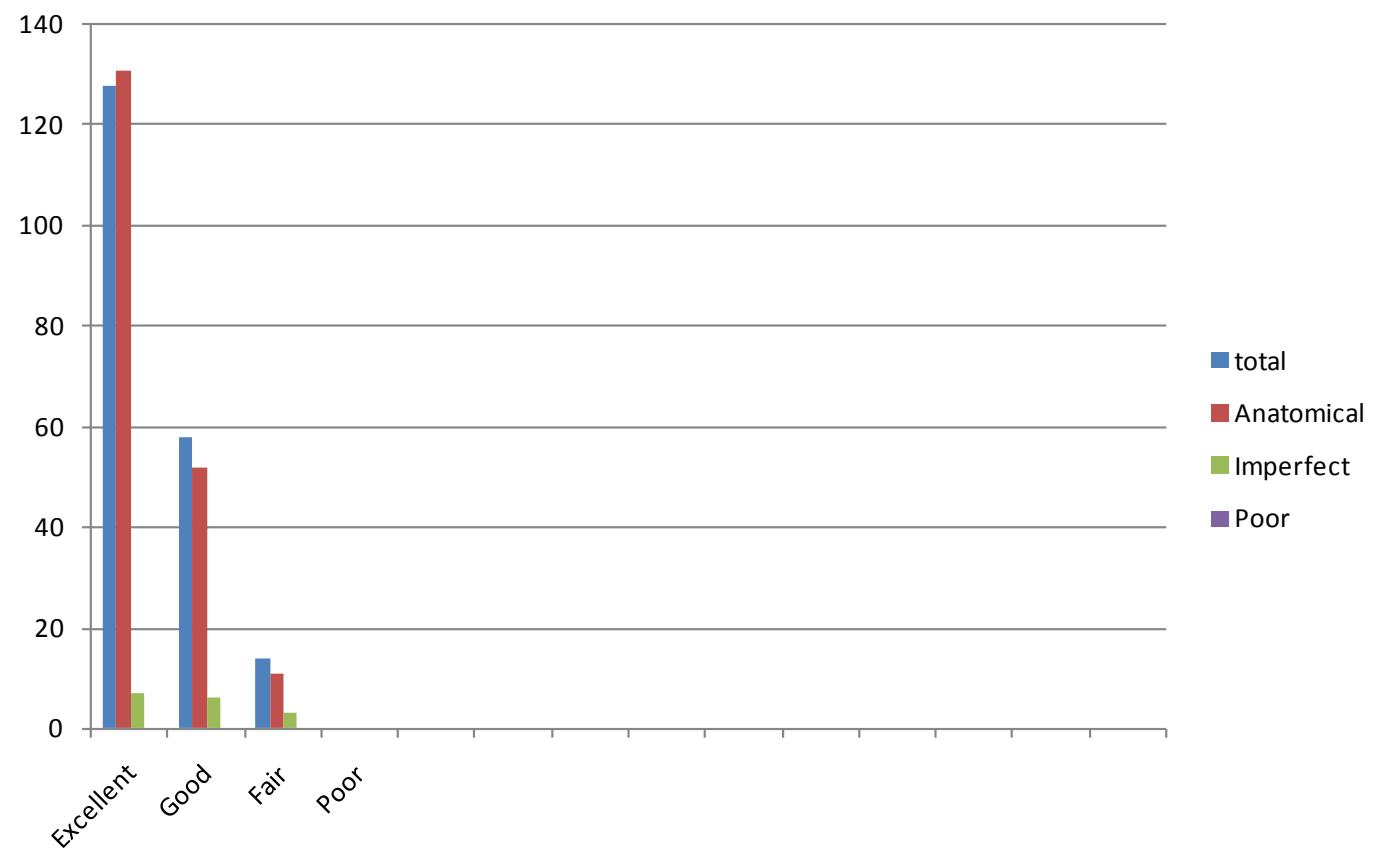

Figure 6. Correlation between functional outcome and radiological outcome of complex acetabulum fracture in 200 cases $(\mathrm{P}<0.004)$.

\section{Discussion}

Fractures of the acetabulum occur when the head of the femur is driven into the pelvis [36]. Therefore, a complex acetabular fracture is a high energy injury and is in risk of poor outcome albeit regardless of the treatment method. A Study in local hospital in 


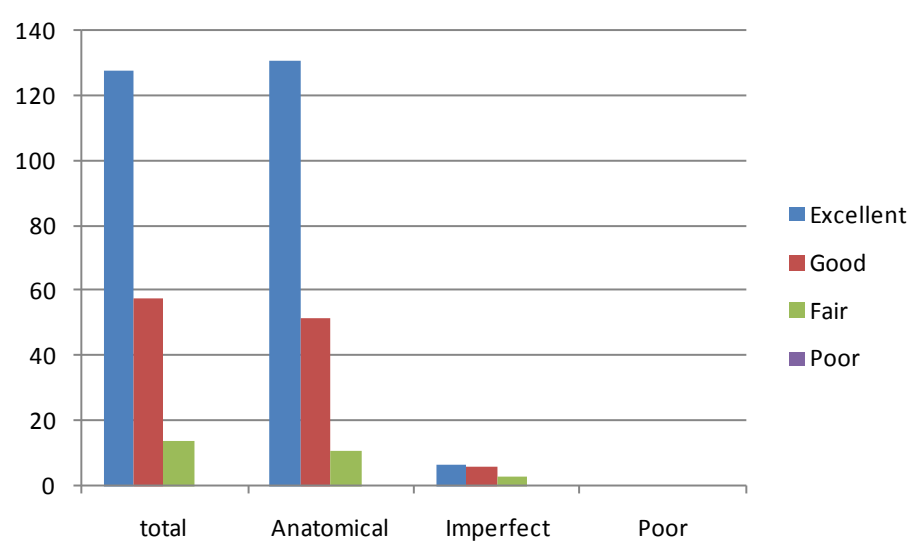

Figure 7. Correlation between functional outcome and reductional outcome of complex acetabulum fracture in 200 cases $(\mathrm{P}<0.003)$.

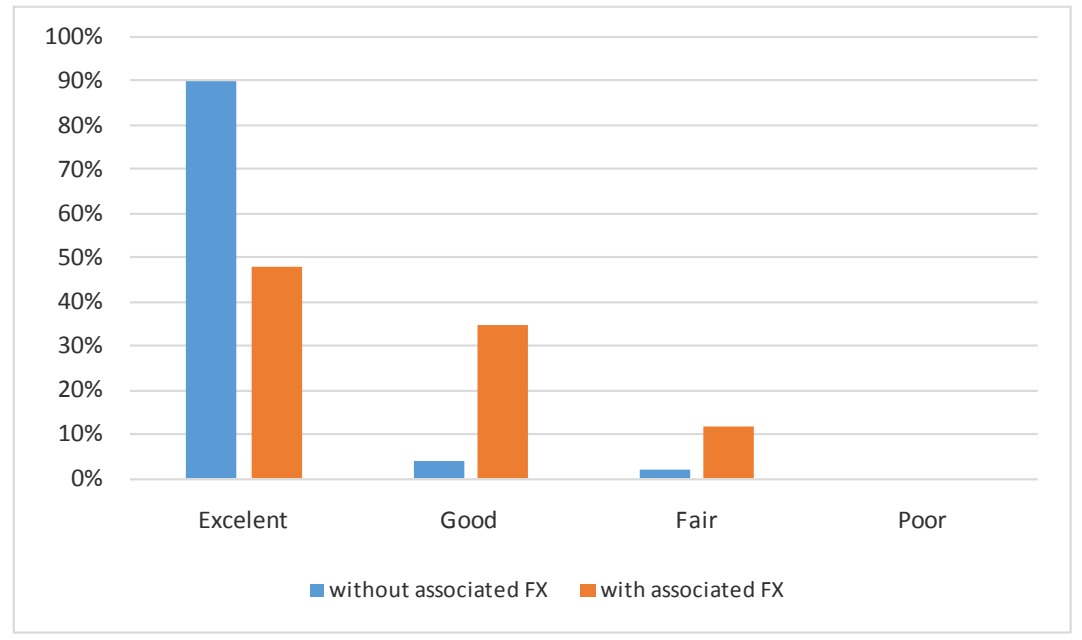

Figure 8. Associated fracture effects on functional outcome in 200 cases of complex acetabulum fracture $(\mathrm{P}<0.005)$.

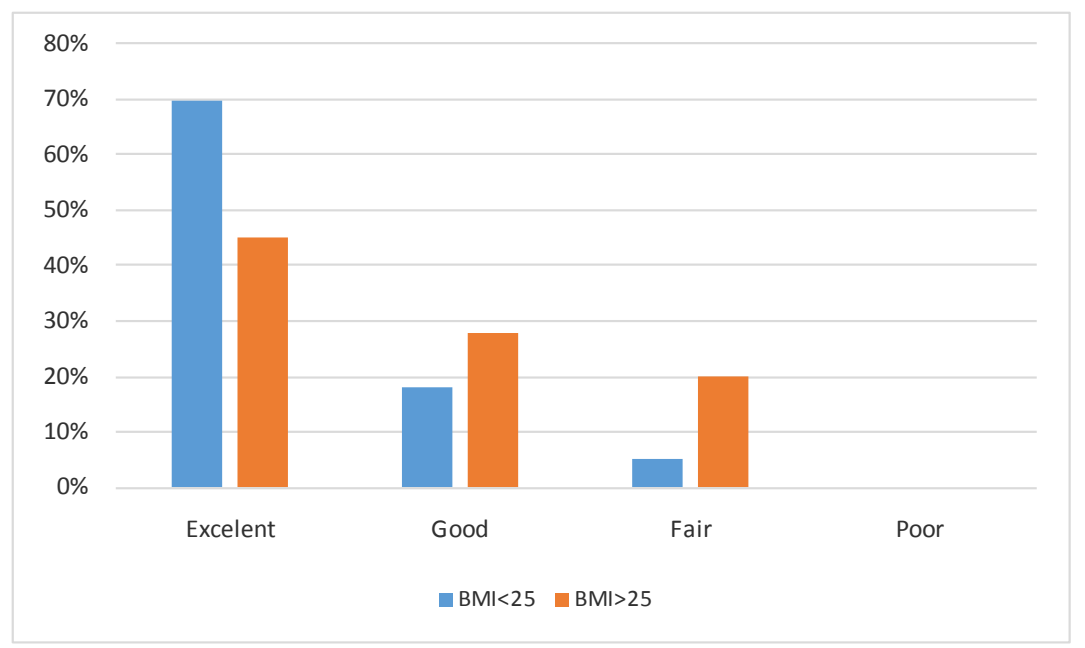

Figure 9. BMI effects on functional outcome in 200 cases of complex acetabulum fracture $(\mathrm{P}<$ $0.004)$. 
Table $1 . \mathrm{BMI}=$ Body mass index $/ \mathrm{M}=$ male $/ \mathrm{F}=$ Female $/ \mathrm{CA}=$ Car accident $/ \mathrm{HF}=$ High fall $/ \mathrm{SP}=\mathrm{Sport}$ injury $/ \mathrm{Tib}=\mathrm{Tibia}$ Fx $/ \mathrm{Fem}=$ Femur Fx/ Acet = both Acetabulum Fx/Bo = Both Column Fx/ PP $=$ Post Column + post wall Fx/ AP = Ant Column + post Hemi transverse FX/ T= Transverse Fx/ AVN= Avascular necrosis/ DVT = Deep vein thrombosis/ INF = Infection/ HO = Heterotopic ossification/ $\mathrm{SCI}=$ Sciatic neuropraxy/ ART $=$ Hip arteritis.

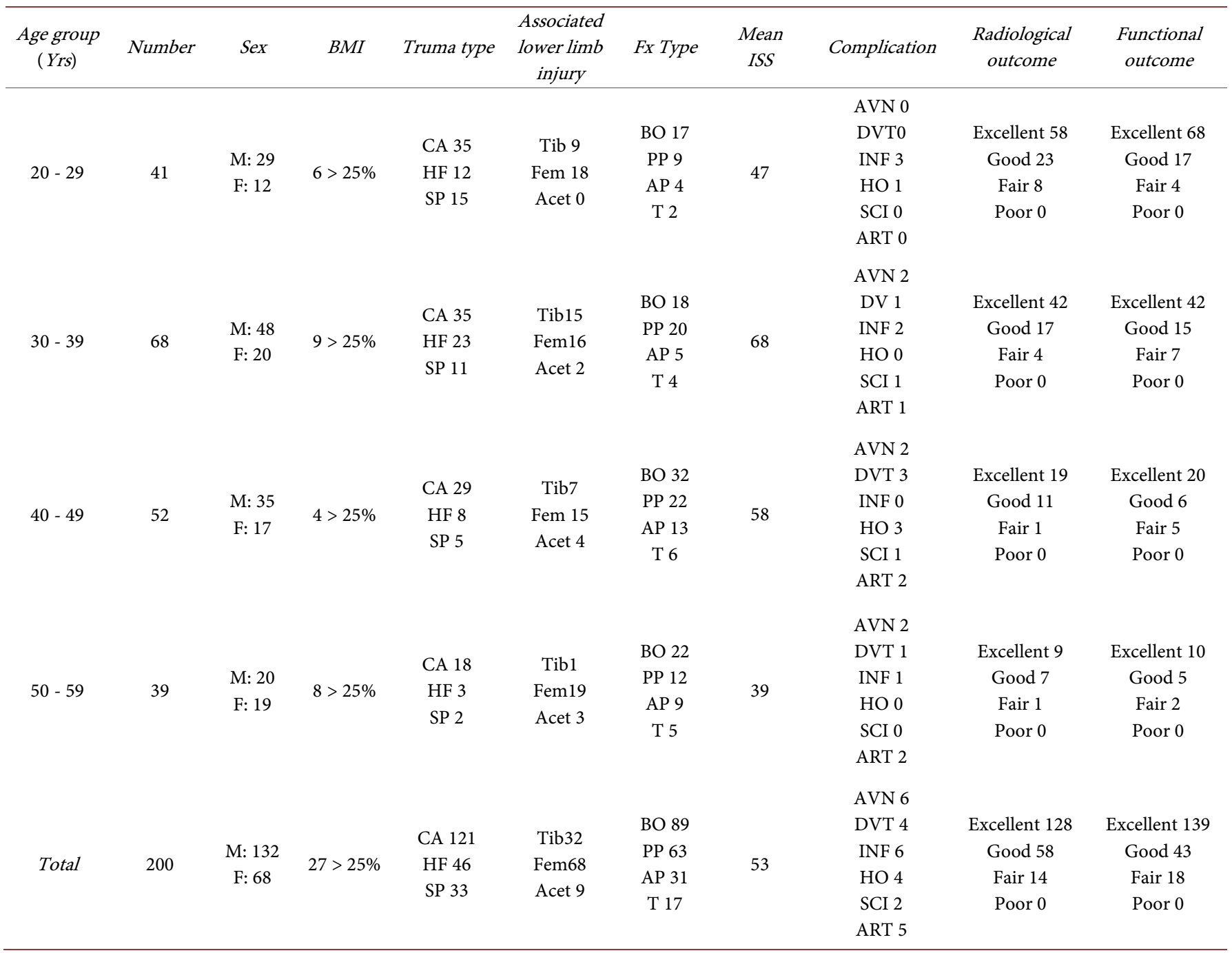

India has confirmed that surgical fixation of fractures of the acetabulum could achieved to an excellent result (74.6\%) of the cases using the ilio-inguinal approach [37]. which was near to our study. Studies have confirmed our research that there is a positive association between the accuracy of reduction and a better long-term result [38] [39] [40] [41]. Although, many series have shown that even when these goals are achieved, but posttraumatic arthritis still occurs in as many as $30 \%$ of patients which is in the lowest. We can assume with proper surgical reduction and internal stabilization techniques can expect a good to excellent recovery following surgery, provided that the hip can be properly aligned and fixed. The fracture pattern, marginal impaction and residual displacement of $>2 \mathrm{~mm}$ are known to be associated with the development ofarthritis [42]-[47]. Naseem Munshi and et al. operated 75 patients with acetabulum fracture who 
were operated with ORIF was achieved to anatomicalposition in 66 (88\%) patients. Their study shows an excellent functional outcome in 18 (24\%), good results in 41 (54.6\%), fair results in 12 (16\%), and poor results in 4 (5.4\%) patients [48]. The contributing factors may include an imperfect reduction, osteochondral defects in either the acetabulumor the femur at the time of injury, osteoarthritis, and avascular necrosis of thefemoral head, heterotropic ossification, sciatic nerve injury andinfection. Postoperative complications included infection at site of surgery [5 (6.7\%)], heterotrophic ossification [3 (4\%)], sciatic nerve injury [10 (13.3\%)], avascular Necrosis of head of femur 3 (4\%)] [48]. Early surgical intervention and experienced management are prime factors in our study that could achieve to better results [49]. However, infection rate has been reduced by using sterile devices, antibiotic therapy, conservative debridement, change of infected implant, and prolongrehabilitation, morbidity and mortality [49]. A meta-analysis to evaluate the classification, the incidence of complications and the functional outcome of patients who had undergone operative treatment of such injuries was undertaken in which the authors analyzed a total of 3670 fractures of acetabulum fixed surgically. The meta-analysis demonstrated an overall incidence of post-traumatic nervepalsies associated with acetabular fractures of $16.4 \%$ [50]. In our study articular congruity reconstruction and stable fixation reduces the incidence of posttraumatic osteoarthritis [51]. Narender Kumar and et al. retrospectively analyzed Twenty-five patients who underwent open reduction and internal fixation (ORIF) for posterior wall acetabular fractures. Anatomic reduction was achieved in 22 hips, imperfect in four. Radiological outcome revealed excellent results in ten hips, good in eight, fair in five and poor in three. However, the presence of associated lower-limb injuries and BMI > 25 adversely affects a satisfactory final outcome in patients with posterior wall acetabular fractures [51] [52] [53].

\section{Conclusion}

In conclusion, we achieved to proper anatomic reduction in following up long term functional and radiologic outcomes. We identified that the functional outcome after open reduction and internal fixation of complex acetabulum fractures depends on fracture type, on time surgery and perfect reduction and avoiding complications which depends on surgical expertise of surgeon. However, even in patients with anatomical reduction, the presence of associated injuries in the lower limb, a high BMI, high degree displacement and inappropriate rehabilitation and physical therapy adversely affect final functional outcome and could be known as a bad prognostic factors.

\section{Acknowledgements}

Thanks to all our patients. We would like to acknowledge Emam Reza and Taleghani Hospital staffs for their assistance in gathering data of this paper.

\section{Conflict of Interest Statement}

None were declared for all authors. 


\section{References}

[1] Hill, R.M., Robinson, C.M. and Keating, J.F. (2001) Fractures of the Pubic Rami. Epidemiology and Five-Year Survival. Journal of Bone \& Joint Surgery - British Volume, 83, 1141-1144. https://doi.org/10.1302/0301-620X.83B8.11709

[2] Gansslen, A., Pohlemann, T., Paul, C., Lobenhoffer, P., Tscherne, H., Gansslen, A., et al. (1996) Epidemiology of Pelvic Ring Injuries. Injury, 27, 13-20. https://doi.org/10.1016/S0020-1383(96)90106-0

[3] Moreno, C., Moore, E.E., Rosenberger, A. and Cleveland, H.C. (1986) Hemorrhage Associated with Major Pelvic Fracture: A Multispecialty Challenge. Journal of Trauma-Injury Infection \& Critical Care, 26, 987-994. https://doi.org/10.1097/00005373-198611000-00005

[4] Mucha, P.J. and Farnell, M.B. (1984) Analysis of Pelvic Fracture Management. Journal of Trauma-Injury Infection \& Critical Care, 24, 379-386. https://doi.org/10.1097/00005373-198405000-00002

[5] Siegel, J.H., Mason-Gonzalez, S., Dischinger, P., Cushing, B., Read, K., Robinson, R., et al. (1993) Safety Belt Restraints and Compartment Intrusions in Frontal and Lateral Motor Vehicle Crashes: Mechanisms of Injuries, Complications, and Acute Care Costs. Journal of Trauma-Injury Infection \&Critical Care, 34, 736-758. https://doi.org/10.1097/00005373-199305000-00017

[6] Ferrera, P.C. and Hill, D.A. (1999) Good Outcomes of Open Pelvic Fractures. Injury, 30, 187-190. https://doi.org/10.1016/S0020-1383(98)00246-0

[7] Gustavo, P.J., Coimbra, R. and Rasslan, S., Oliveira, A., Fregoneze, M., Mercadante, M., et al. (2000) The Role of Associated Injuries on Outcome of Blunt Trauma Patients Sustaining Pelvic Fractures. Injury, 31, 677-682.

[8] Gansslen, A., Pohlemann, T., Paul, C., Lobenhoffer, P., Tscherne, H., Gansslen, A., et al. (1996) Epidemiology of Pelvic Ring Injuries. Injury, 27, 13-20.

https://doi.org/10.1016/S0020-1383(96)90106-0

[9] Brenneman, F.D., Katyal, D., Boulanger, B.R., Tile, M. and Redelmeier, D.A. (1997) Long-Term Outcomes in Open Pelvic Fractures. Journal of Trauma-Injury Infection \& Critical Care, 42, 773-777. https://doi.org/10.1097/00005373-199705000-00003

[10] Poole, G.V., Ward, E.F., Muakkassa, F.F., Hsu, H.S., Griswold, J.A. and Rhodes, R.S. (1991) Pelvic Fracture from Major Blunt Trauma. Outcome Is Determined by Associated Injuries. Annals of Surgery, 213, 532-538. https://doi.org/10.1097/00000658-199106000-00002

[11] Boulanger, B.R., Milzman, D., Mitchell, K. and Rodriguez, A. (1992) Body Habitus as a Predictor of Injury Pattern after Blunt Trauma. Journal of Trauma-Injury Infection \& Critical Care, 33, 228-232. https://doi.org/10.1097/00005373-199208000-00011

[12] Dias, M., Goldsztajn, F., Guimarães, J., Grizendi, J., Correia, M. and Rocha, T. (2010) Epidemiology of Acetabulum Fractures Treated at the Instituto National de Traumatologia E Orthopedia (INTO). Revista Brasileira de Ortopedia, 45, 474-477. https://doi.org/10.1016/S2255-4971(15)30438-9

[13] Peltier, L.F. (1962) Complications Associated with Fractures of the Pelvis. Journal of Bone \& Joint Surgery, 47, 1060-1069. https://doi.org/10.2106/00004623-196547050-00018

[14] Anizar-Faizi, A., Hisam, A., Sudhagar, K., Moganadass, M. and Suresh, C. (2014) Outcome of Surgical Treatment for Displaced Acetabular Fractures. Malaysian Orthopaedic Journal, 8, 1-6.

[15] El-Khadrawe, T.A., Hammad, A.S. and Hassaan, A.E. (2012) Indicators of Outcome after Internal Fixation of Complex Acetabular Fractures. Alexandria Journal of Medicine, 48, 99107. https://doi.org/10.1016/j.ajme.2011.12.005 
[16] Kinik, H. and Armangil, M. (2014) Extensile Triradiate Approach in the Management of Combined Acetabular Fractures. Archives of Orthopaedic and Trauma Surgery, 124, 476482.

[17] Griffin, D.B., Beaule, P.E. and Matta, J.M. (2005) Safety and Efficacy of the Extended Iliofemoral Approach in the Treatment of Complex Fractures of the Acetabulum. Journal of Bone \& Joint Surgery, 87, 1391-1396. https://doi.org/10.1302/0301-620X.87B10.16538

[18] Petsatodis, G., Antonarakos, P., Chalidis, B., Papadopoulos, P., Christoforidis, J. and Pournaras, J. (2007) Surgically Treated Acetabular Fractures via a Single Posterior Approach with a Follow-Up of 2-10 Years. Injury, 38, 334-343. https://doi.org/10.1016/j.injury.2006.09.017

[19] Routt, M.L. and Swiontkowski, M.F. (1990) Operative Treatment of Complex Acetabular Fractures. Combined Anterior and Posterior Exposures during the Same Procedure. Journal of Bone \& Joint Surgery, 72, 897-904. https://doi.org/10.2106/00004623-199072060-00016

[20] Putnis, S.E., Dala-Ali, B.M. and Bircher, M. (2007) Posterior Wall Osteotomy to Facilitate Reduction of Complex Acetabular Fractures. Injury, 38, 1214-1217. https://doi.org/10.1016/j.injury.2006.09.022

[21] Reinert, C.M., Bosse, M.J., Poka, A., Schacherer, T., Brumback, R.J. and Burgess, A.R. (1988) A Modified Extensile Exposure for the Treatment of Complex or Malunited Acetabular Fractures. Journal of Bone \& Joint Surgery, 70, 329-337. https://doi.org/10.2106/00004623-198870030-00003

[22] Hoffmann, R., Stockle, U., Nittinger, M., Sudkamp, N.P. and Haas, N.P. (2000) Operative Treatment of Complex Acetabular Fractures through the Modified Extensile Iliofemoral Approach. Unfallchirurg, 103, 12-21. https://doi.org/10.1007/s001130050003

[23] Helfet, D.L. and Schmeling, G.J. (1994) Management of Complex Acetabular Fractures through Single Nonextensile Exposures. Clinical Orthopaedics and Related Research, 305, 58-68. https://doi.org/10.1097/00003086-199408000-00009

[24] Stockle, U., Hoffmann, R., Sudkamp, N.P., Reindl, R. and Haas, N.P. (2002) Treatment of Complex Acetabular Fractures through a Modified Extended Iliofemoral Approach. Journal of Orthopaedic Trauma, 16, 220-230. https://doi.org/10.1097/00005131-200204000-00002

[25] Gansslen, A. and Krettek, C. (2009) Internal Fixation of Acetabular Both-Column Fractures via the Ilioinguinal Approach. Operative Orthopädie und Traumatologie, 21, 270-282.

[26] Genuario, J., Koval, K.J., Cantu, R.V. and Spratt, K.F. (2008) Does Hospital Surgical Volume Affect In-Hospital Outcomes in Surgically Treated Pelvic and Acetabular Fractures? Bulletin of the NYU Hospital for Joint Diseases, 66, 282-289.

[27] Giannoudis, P.V., Grotz, M.R.W., Papakostidis, C. and Dinopoulos, H. (2005) Operative Treatment of Displaced Fractures of the Acetabulum: A Meta-Analysis. Journal of Bone \& Joint Surgery, 87, 2-9.

[28] Kim, H.T., Ahn, J.-M., Hur, J.-O., Lee, J.-S. and Cheon, S.-J. (2011) Reconstruction of Acetabular Posterior Wall Fractures. Clinics in Orthopedic Surgery, 3, 114-120. https://doi.org/10.4055/cios.2011.3.2.114

[29] Porter, S.E., Schroeder, A.C., Dzugan, S.S., Graves, M.L., Zhang, L. and Russell, G.V. (2008) Acetabular Fracture Patterns and Their Associated Injuries. Journal of Orthopaedic Trauma, 22, 165-170. https://doi.org/10.1097/BOT.0b013e318165918b

[30] Milenkovic, S., Saveski, J., Radenkovic, M., Vidic, G. and Trajkovska, N. (2011) Surgical Treatment of Displaced Acetabular Fractures. Srpski Arhiv za Celokupno Lekarstvo, 139, 496-500. https://doi.org/10.2298/SARH1108496M 
[31] Kaempffe, F.A., Bone, L.B. and Border, J.R. (1991) Open Reduction and Internal Fixation of Acetabular Fractures: Heterotopic Ossification and Other Complications of Treatment. Journal of Orthopaedic Trauma, 5, 439-445. https://doi.org/10.1097/00005131-199112000-00009

[32] Wright, R., Barrett, K., Christie, M.J. and Johnson, K.D. (1994) Acetabular Fractures: Long-Term Follow-Up of Open Reduction and Internal Fixation. Journal of Orthopaedic Trauma, 8, 397-403. https://doi.org/10.1097/00005131-199410000-00005

[33] Baker, S.P., O’Neill, B.,, Haddon, W. and Long, W.B. (1974) The Injury Severity Score: A Method for Describing Patients with Multiple Injuries and Evaluating Emergency Care. Journal of Trauma-Injury Infection \& Critical Care, 14, 187-196. https://doi.org/10.1097/00005373-197403000-00001

[34] Durkee, N.J., Jacobson, J., Jamadar, D., Karunakar, M.A., Morag, Y. and Hayes, C. (2006) Classification of Common Acetabular Fractures: Radiographic and CT Appearances. American Journal of Roentgenology, 187, 915-925. https://doi.org/10.2214/AJR.05.1269

[35] Letournel, E. (1980) Acetabulum Fractures: Classification and Management. Clinical Orthopaedics and Related Research, 151, 81-106. https://doi.org/10.1097/00003086-198009000-00012

[36] Matta, J.M., Anderson, L.M., Epstein, H.C. and Hendricks, P. (1986) Fractures of Acetabulum: A Retrospective Analysis. Clinical Orthopaedics and Related Research, 205, 230-240.

[37] Mears, D.C., Velyvis, J.H. and Chang, C.P. (2003) Displaced Acetabular Fractures Managed Operatively: Indicators of Outcome. Clinical Orthopaedics and Related Research, 407, 173-186. https://doi.org/10.1097/00003086-200302000-00026

[38] Milenkovic, S., Saveski, J., Radenkovic, M., Vidic, G. and Trajkovska, N. (2011) Surgical Treatment of Displaced Acetabular Fractures. Srpski Arhiv za Celokupno Lekarstvo, 139, 496-500. https://doi.org/10.2298/SARH1108496M

[39] Matta, J.M. (1996) Fractures of the Acetabulum: Accuracy of Reduction and Clinical Results in Patients Managed Operatively within Three Weeks after the Injury. Journal of Bone \& Joint Surgery, 78, 1632-1645. https://doi.org/10.2106/00004623-199611000-00002

[40] Wright, R., Barrett, K., Christie, M.J. and Johnson, K.D. (1994) Acetabular Fractures: Long-Term Follow-Up of Open Reduction and Internal Fixation. Journal of Orthopaedic Trauma, 8, 397-403. https://doi.org/10.1097/00005131-199410000-00005

[41] Chiu, F.Y., Chen, C.M. and Lo, W.H. (2000) Surgical Treatment of Displaced Acetabular Fractures: 72 Cases Followed for 10 (6-14) Years. Injury, 31, 181-185. https://doi.org/10.1016/S0020-1383(99)00277-6

[42] Osgood, G., Manson, T.T., O’Toole, R.V. and Turen, C.H. (2013) Combined Pelvic Ring Disruption and Acetabular Fracture: Associated Injury Patterns in 40 Patients. Journal of Orthopaedic Trauma, 27, 243-247. https://doi.org/10.1097/BOT.0b013e31826c2751

[43] Olson, S.A. (2005) CT-Based Acetabular Fracture Classification. American Journal of Roentgenology, 185, 277-278. https://doi.org/10.2214/ajr.185.1.01850277b

[44] Moed, B.R., WillsonCarr, S.E. and Watson, J.T. (2002) Results of Operative Treatment of Fractures of the Posterior Wall of the Acetabulum. Journal of Bone \& Joint Surgery, 84, 752-758. https://doi.org/10.2106/00004623-200205000-00008

[45] Mayo, K.A. (1994) Open Reduction and Internal Fixation of Fractures of the Acetabulum. Results in 163 Fractures. Clinical Orthopaedics and Related Research, 305, 31-37. https://doi.org/10.1097/00003086-199408000-00005

[46] Pennal, G.F., Davidson, J., Garside, H. and Plewes, J. (1980) Results of Treatment of acetaBular Fractures. Clinical Orthopaedics and Related Research, 151, 115-123. 
[47] Ragnarsson, B. and Mjoberg, B. (1992) Arthrosis after Surgically Treated Acetabular Fractures. A Retrospective Study of 60 Cases. Acta Orthopaedica Scandinavica, 63, 511-514. https://doi.org/10.3109/17453679209154725

[48] Munshi, N., Abbas, A., Gulamhussein, M., Mehboob, G. and Qureshi, R. (2015) Functional Outcome of the Surgical Management of Acute Acetabular Fractures. Journal of Acute Disease, 4, 327-330. https://doi.org/10.1016/j.joad.2015.06.011

[49] Hadley, N.A., Brown, T.D. and Weinstein, S.L. (1990) The Effects of Contact Pressure Elevations and Aseptic Necrosis on the Long-Term Outcome of Congenital Hip Dislocation. Journal of Orthopaedic Research, 8, 504-513. https://doi.org/10.1002/jor.1100080406

[50] Kumar, A., Shah, N.A., Kershaw, S.A. and Clayson, A.D. (2005) Operative Management of Acetabular Fractures: A Review of 73 Fractures. Injury, 36, 605-612. https://doi.org/10.1016/j.injury.2004.11.022

[51] Magu, N.K., Rohilla, R. and Arora, S. (2012) Conservatively Treated Acetabular Fractures: A Retrospective Analysis. Indian Journal of Orthopaedics, 46, 36-45. https://doi.org/10.4103/0019-5413.91633

[52] Mardanpour, K. and Rahbar, M. (2013) The Outcome of Surgically Treated Traumatic Unstable Pelvic Fractures by Open Reduction and Internal Fixation. Journal of Injury and Violence Research, 5, 77-83. https://doi.org/10.5249/jivr.v5i2.138

[53] Mardanpour, K. and Rahbar, M. (2013) Open Reduction and Internal Fixation of Intraarticular Fractures of the Humerus: Evaluation of 33 Cases. Trauma Monthly, 17, 396-400. https://doi.org/10.5812/traumamon.5278

\section{Submit or recommend next manuscript to SCIRP and we will provide best service for you:}

Accepting pre-submission inquiries through Email, Facebook, LinkedIn, Twitter, etc.

A wide selection of journals (inclusive of 9 subjects, more than 200 journals)

Providing 24-hour high-quality service

User-friendly online submission system

Fair and swift peer-review system

Efficient typesetting and proofreading procedure

Display of the result of downloads and visits, as well as the number of cited articles

Maximum dissemination of your research work

Submit your manuscript at: http://papersubmission.scirp.org/

Or contact ojo@scirp.org 